\title{
ITO-Schottky Photodiodes for High-Performance Detection in the UV-IR Spectrum
}

\author{
Necmi Biyikli, Student Member, IEEE, Ibrahim Kimukin, Student Member, IEEE, \\ Bayram Butun, Student Member, IEEE, Orhan Aytür, Senior Member, IEEE, and Ekmel Ozbay, Member, IEEE
}

\begin{abstract}
High-performance vertically illuminated Schottky photodiodes with indium-tin-oxide (ITO) Schottky layers were designed, fabricated, and tested. Ternary and quarternary III-V material systems (AlGaN-GaN, AlGaAs-GaAs, InAlGaAs-InP, and InGaAsP-InP) were utilized for detection in the ultraviolet (UV) $(\lambda<400 \mathrm{~nm})$, near-IR $(\lambda \sim 850 \mathrm{~nm})$, and IR $(\lambda \sim 1550 \mathrm{~nm})$ spectrum. The material properties of thin ITO films were characterized. Using resonant-cavity-enhanced (RCE) detector structures, improved efficiency performance was achieved. Current-voltage, spectral responsivity, and high-speed measurements were carried out on the fabricated ITO-Schottky devices. The device performances obtained with different material systems are compared.
\end{abstract}

Index Terms-Heterostructure, high performance, III-V alloys, indium-tin-oxide (ITO), photodiode, resonant cavity, Schottky.

\section{INTRODUCTION}

$\mathbf{P}$ HOTODETECTORS based on III-V semiconductors have demonstrated high-performance detection in a wide spectrum range with cutoff wavelengths ranging from UV to far-IR [1]. Main photodetector performance parameters include dark current, quantum efficiency, and bandwidth [2]. The bandwidth-efficiency (BWE) product is a common figure of merit for photodetectors. This product is limited by the well-known BWE tradeoff for conventional vertically illuminated detectors [3]. Two approaches were offered to beat this BWE limit: resonant-cavity-enhanced (RCE) detectors and edge-coupled detectors. RCE detectors benefit from the recycle process of resonant photons within the detector cavity, which results in selectively enhanced efficiency performance [4]. Edge-coupled detector structures, on the other hand, decouple the dependence of efficiency and bandwidth [5]. Both structures have proved their potential for use as high-performance photodetectors [6]-[11].

Among several types of photodetectors, Schottky photodiodes are particularly attractive due to their unipolar structure. Schottky detectors are majority carrier devices and do not suffer from minority carrier diffusion, which makes them suitable for high-speed applications. The ease of growth and fabrication is another advantage of Schottky photodiodes. However,

Manuscript received February 11, 2004; revised July 11, 2004. This work was supported in part by NATO under Grant SfP971970 and by the Turkish Department of Defense under Grant KOBRA-002 and Grant FUSAM-03. The work of E. Ozbay was supported by the Turkish Academy of Sciences.

N. Biyikli, B. Butun, and O. Aytür are with the Department of Electrical and Electronics Engineering, Bilkent University, Bilkent, Ankara 06800, Turkey (e-mail: biyikli@ee.bilkent.edu.tr).

I. Kimukin and E. Ozbay are with the Department of Physics, Bilkent University, Bilkent, Ankara 06800, Turkey.

Digital Object Identifier 10.1109/JSTQE.2004.833977 conventional vertically illuminated Schottky photodiodes with metallic Schottky contacts suffer from low-efficiency performance, mainly caused by the absorptive and reflective Schottky contact layers. To overcome this drawback, transparent conductors like ITO were proposed as Schottky contact materials for low-loss Schottky photodiodes [12]. As a result, high-performance ITO-Schottky photodiodes were demonstrated on different material systems [13], [14].

Recently, we have demonstrated ITO-Schottky photodiodes on AlGaAs-GaAs [15] and AlGaN-GaN [16]-[18] material systems for near-IR and UV detection, respectively. In this paper, we review our ITO-Schottky research and present the measurement results of our newly fabricated IR $(\lambda \sim 1.55 \mu \mathrm{m})$ RCE ITO-Schottky photodiodes on InAlGaAs-InP and InGaAsP-InP heterostructures. A comparative analysis between different material systems is done in terms of detector performance.

\section{EXPERIMENTAL WORK}

\section{A. Material Properties of Thin ITO Films}

Thin ITO films were grown using a composite target $\left(\mathrm{SnO}_{2}\right.$ : $\left.\mathrm{In}_{2} \mathrm{O}_{3}=1: 9\right)$ under Ar plasma in an RF-magnetron sputtering system. ITO films were deposited at a rate around $2 \AA / \mathrm{s}$. To determine the electrical properties of ITO, a 100-nm-thick ITO film was deposited on a semi-insulating GaAs sample. Au transmission line patterns were formed on top of the ITO layer to measure the film resistivity. The resistivity of the as-grown ITO film was $2 \times 10^{-4} \Omega$-cm. With a 1 -min annealing at $400{ }^{\circ} \mathrm{C}$, a resistivity of $1.2 \times 10^{-4} \Omega$-cm was achieved.

The optical transmission properties of ITO films $(\sim 100 \mathrm{~nm}$ thick) were characterized using a fiber-optic based transmission/reflection measurement setup. The output of a deuterium-tungsten light source was coupled into a multimode solarization-resistant optical fiber. The samples were illuminated by this fiber output. The transmitted/reflected light was collected by another UV fiber which sent the transmitted light to the spectrometer. Thin films were deposited on quartz samples. To make a comparison with semitransparent $\mathrm{Au}$ films, $\sim 100$ - $\AA$-thick Au films were also prepared. The measured transmission and reflection spectra of ITO and Au films in the 200-1700-nm region are shown in Fig. 1(a) and (b), respectively. Transmittivity of ITO showed a sharp increase around $300 \mathrm{~nm}$ and stays above $75 \%$ for $\lambda>380 \mathrm{~nm}$. For $>80 \%$, transmission was observed within $680-1700 \mathrm{~nm}$. Au film exhibited a transmission peak around $550 \mathrm{~nm}$. Except for the 340-870-nm 

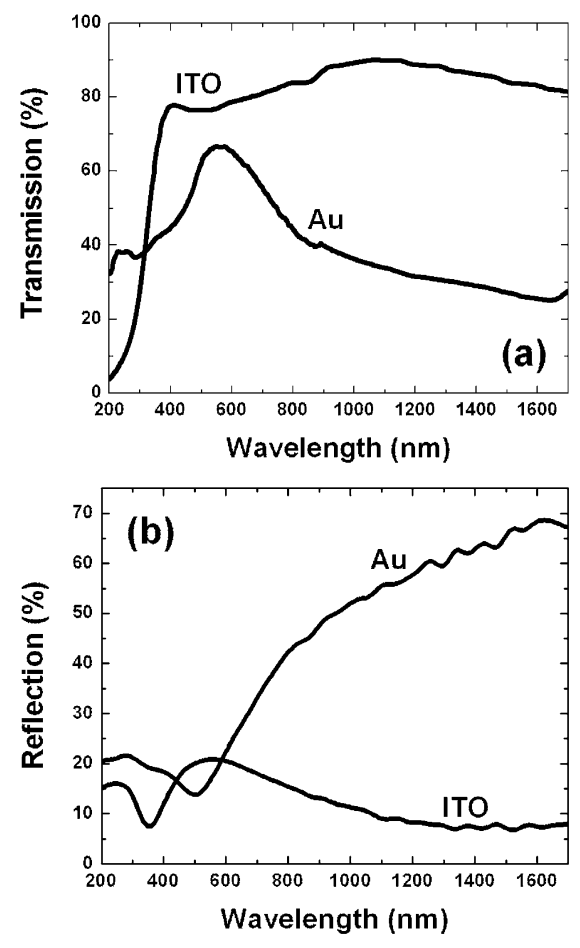

Fig. 1. (a) Measured spectral transmittivity of ITO and Au films. (b) Measured spectral reflectivity curves of the same films.

region, the transmittivity of Au film was below $40 \%$. The reflectivity of ITO film was smaller than $20 \%$ throughout the measurement range. Au displayed an increasing reflectivity toward the IR spectrum, reaching nearly $70 \%$ around 1600 $\mathrm{nm}$. Using the transmittivity and reflectivity data, absorption spectrum of the films was calculated. Fig. 2 shows the spectral absorption curve of the films. ITO was nearly lossless in the 570-1240-nm range with less than $2 \%$ absortion. This transparency failed in the UV region and the optical loss in ITO film increased significantly toward shorter wavelengths. The absorption of ITO film exceeded the loss induced by Au film for wavelengths smaller than $330 \mathrm{~nm}$ (see inset figure). Optical loss in ITO film increased slightly toward IR wavelengths reaching a loss of $10 \%$ at $1700 \mathrm{~nm}$. Au film exhibited a relatively strong absorption in the UV spectrum with a $40 \%$ peak around $300 \mathrm{~nm}$. The absorption of $\mathrm{Au}$ film decreased toward the $\sim 10 \%$ level at the visible (VIS) spectrum and fluctuated around this value in the IR region. These results proved that ITO could be used as low-loss Schottky contacts for detectors operating at wavelengths greater than $330 \mathrm{~nm}$, particularly in the VIS-IR spectrum.

\section{B. Design of Photodiode Structures}

The detector structures were designed using a transfer matrix method (TMM)-based simulation program. Using the complex refractive index data of used materials, the desired layer thicknesses were found. Six different photodiode structures were designed using four different material systems. Four of them were RCE structures while two designs consisted of conventional single-pass structures. The III-V alloys used for UV, NIR, and

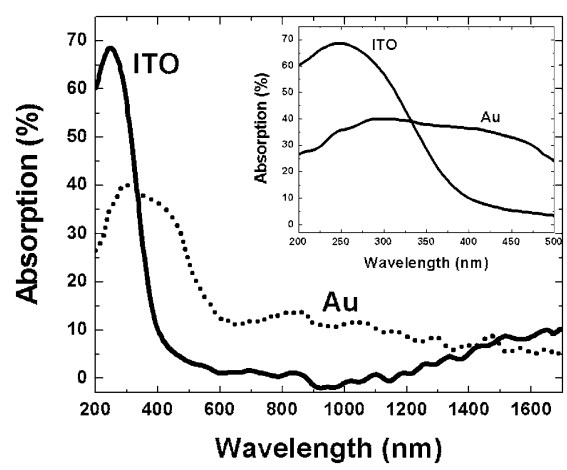

Fig. 2. Absorption spectrum of ITO and Au films. Inset shows the same data for wavelengths smaller than $500 \mathrm{~nm}$.

IR detectors were AlGaN, AlGaAs, and InAlGaAs-InGaAsP, respectively.

The wide-bandgap $\mathrm{Al}_{x} \mathrm{Ga}_{1-x} \mathrm{~N}$ alloy provides a naturally visible-blind detector material with a cutoff wavelength smaller than $363 \mathrm{~nm}$ (corresponding to the 3.4-eV bandgap of $\mathrm{GaN}$ ). With $x>0.38, \mathrm{Al}_{x} \mathrm{Ga}_{1-x} \mathrm{~N}$ becomes naturally solar-blind with a cutoff around $280 \mathrm{~nm}$. Using this alloy, three UV detector structures were designed: a single-pass visible-blind homojunction $\mathrm{GaN}$ structure, a single-pass $\mathrm{AlGaN}$ structure, and an RCE visible-blind AlGaN structure. The active layer of the homojunction $\mathrm{GaN}$ design was $0.3 \mu \mathrm{m}$ thick. The single-pass AlGaN detector had a $0.8-\mu$ m-thick $\mathrm{Al}_{0.38} \mathrm{Ga}_{0.62} \mathrm{~N}$ absorption layer. The ohmic contact layer was formed with GaN. The UV RCE detector consisted of a thin 70-nm GaN absorption layer, $\mathrm{Al}_{0.2} \mathrm{Ga}_{0.8} \mathrm{~N}$ ohmic contact layer and a 20 pair bottom $\mathrm{AIN}-\mathrm{Al}_{0.2} \mathrm{Ga}_{0.8} \mathrm{~N}$ Bragg mirror centered at $\sim 350 \mathrm{~nm}$. The details of the epitaxial structures can be found elsewhere [16]-[18].

The $\mathrm{Al}_{x} \mathrm{Ga}_{1-x}$ As-based Schottky photodiode structure was an RCE detector design for operation in the first optical communication window $(\lambda \sim 850 \mathrm{~nm})$. Such a detector would be useful for high-bit rate communications in local area networks (LANs).

A 150-nm-thick GaAs layer was utilized as the detector active layer. Other cavity layers were formed with transparent $\mathrm{Al}_{x} \mathrm{Ga}_{1-x}$ As layers with $x>0.2$. The bottom mirror of the cavity was a 24-pair AIAs- $\mathrm{Al}_{0.2} \mathrm{Ga}_{0.8}$ As distributed Bragg reflector (DBR) centered at $820 \mathrm{~nm}$ [15].

For $1.55-\mu \mathrm{m}$ operation, two InP-based heterojunction RCE photodiodes were designed using InGaAs-InAlAs-InAlGaAs and InGaAs-InGaAsP-InP heterostructures. Table I shows the epitaxial structure of InAlGaAs-based RCE Schottky photodiode. The 300-nm-thick InGaAs absorption layer was capped with a 50-nm-thick InAlAs Schottky barrier enhancement layer. Two grading layers surrounding the active layer are designed in order to minimize carrier trapping. The ohmic contact layer was formed with a highly doped InAlAs layer. A low-loss cavity was formed by using transparent cavity and mirror layers. The bottom mirror consisted of a 25-pair InAlAs- $\mathrm{In}_{0.53} \mathrm{Al}_{0.13} \mathrm{Ga}_{0.34} \mathrm{As} \mathrm{DBR}$ centered at $\sim 1550 \mathrm{~nm}$.

The second 1.55- $\mu \mathrm{m}$ RCE Schottky detector design was based on InGaAsP quarternary alloy. Table II shows the details of the epitaxial layers. Similar to InAlGaAs design, a 
TABLE I

INALGAAs-BASEd RCE SCHOTTKY PHOTODIODE STRUCTURE

\begin{tabular}{lll}
\hline Material & Thickness & Doping $\left(\mathrm{cm}^{-3}\right)$ \\
\hline InAlAs & $50 \mathrm{~nm}$ & $\mathrm{~N}-\left(1 \times 10^{16} \mathrm{~cm}^{-3}\right)$ \\
grading & $30 \mathrm{~nm}$ & $\mathrm{~N}-\left(1 \times 10^{16} \mathrm{~cm}^{-3}\right)$ \\
InGaAs & $300 \mathrm{~nm}$ & $\mathrm{~N}-\left(1 \times 10^{16} \mathrm{~cm}^{-3}\right)$ \\
grading & $30 \mathrm{~nm}$ & $\mathrm{~N}-\left(1 \times 10^{16} \mathrm{~cm}^{-3}\right)$ \\
InAlAs & $60 \mathrm{~nm}$ & $\mathrm{~N}-\left(1 \times 10^{16} \mathrm{~cm}^{-3}\right)$ \\
InAlAs & $300 \mathrm{~nm}$ & $\mathrm{~N}+\left(3 \times 10^{18} \mathrm{~cm}^{-3}\right)$ \\
InAlAs & $240 \mathrm{~nm}$ & u. i. d. \\
InAlAs / InAlGaAs & $25 \times(121 \mathrm{~nm}$ & u. i. d. \\
Bragg mirror & $/ 112 \mathrm{~nm})$ & Semi-insulating \\
InF'substrate & $\sim 500 \mu \mathrm{m}$ &
\end{tabular}

TABLE II

INGAASP BASED RCE SCHOTTKY PHOTODIODE STRUCTURE

\begin{tabular}{lll}
\hline Material & Thickness & Doping $\left(\mathrm{cm}^{-3}\right)$ \\
\hline InGaAsP & $30 \mathrm{~nm}$ & $\mathrm{~N}-\left(1 \times 10^{16} \mathrm{~cm}^{-3}\right)$ \\
InGaAs & $300 \mathrm{~nm}$ & $\mathrm{~N}-\left(1 \times 10^{16} \mathrm{~cm}^{-3}\right)$ \\
InGaAsP & $30 \mathrm{~nm}$ & $\mathrm{~N}-\left(1 \times 10^{16} \mathrm{~cm}^{-3}\right)$ \\
InP & $300 \mathrm{~nm}$ & $\mathrm{~N}+\left(3 \times 10^{16} \mathrm{~cm}^{-3}\right)$ \\
InP & $380 \mathrm{~nm}$ & u. i. d. \\
InGaAsP InP & $25 \times(113 \mathrm{~nm}$ & u. i. d. \\
Bragg mirror & $/ 122 \mathrm{~nm})$ & \\
InP substrate & $\sim 500 \mu \mathrm{m}$ & Semi-insulating \\
\hline
\end{tabular}

300-nm-thick InGaAs absorption layer was utilized. A thin $\mathrm{In}_{0.66} \mathrm{Ga}_{0.34} \mathrm{As}_{0.73} \mathrm{P}_{0.27}$ cap layer functioned as a barrier enhancement layer. For ohmic contacts a 300-nm-thick n-type doped InP layer was designed. The bottom mirror of the resonant cavity was formed with a 25-pair $\mathrm{In}_{0.66} \mathrm{Ga}_{0.34} \mathrm{As}_{0.73} \mathrm{P}_{0.27} / \mathrm{InP}$ DBR centered at $\sim 1550 \mathrm{~nm}$. All cavity and mirror layers except the InGaAs absorption layer were transparent around the operation wavelength of $1550 \mathrm{~nm}$.

\section{Fabrication Process}

III-nitride-based UV detector wafers were grown by MOCVD, while other structures were grown by MBE. All ITO-Schottky photodetector samples were fabricated using a microwave compatible fabrication process. Devices with $5 \times 5 \mu \mathrm{m}^{2}$ to $200 \times 200 \mu \mathrm{m}^{2}$ active areas were fabricated using standard III-V semiconductor processing techniques. Layer etching in ohmic contact and mesa isolation process steps were done via dry etching for III-nitride samples using a reactive ion etching (RIE) system. Chemical wet etching with ammonia and phosphoric acid-based etching solutions was used for the other (IR) detector samples. Ohmic contacts on UV and IR detector samples were formed by $\mathrm{Ti}-\mathrm{Al}$ and $\mathrm{Ge}-\mathrm{Au}-\mathrm{Ge}-\mathrm{Au}-\mathrm{Ni}-\mathrm{Au}$ alloys, respectively. To achieve low contact resistance, the samples were annealed in a rapid thermal annealing (RTA) system at temperatures up to $700{ }^{\circ} \mathrm{C}$. ITO-Schottky contacts were deposited via sputtering. The sample surfaces were passivated by an $\mathrm{Si}_{3} \mathrm{~N}_{4}$ layer. Interconnect metal (Ti-Au) pads were deposited by thermal evaporation.

\section{Device Characterization}

The fabricated samples were characterized in terms of current-voltage I-V, spectral quantum efficiency, and high-speed pulse response. All measurements were made onwafer, using a
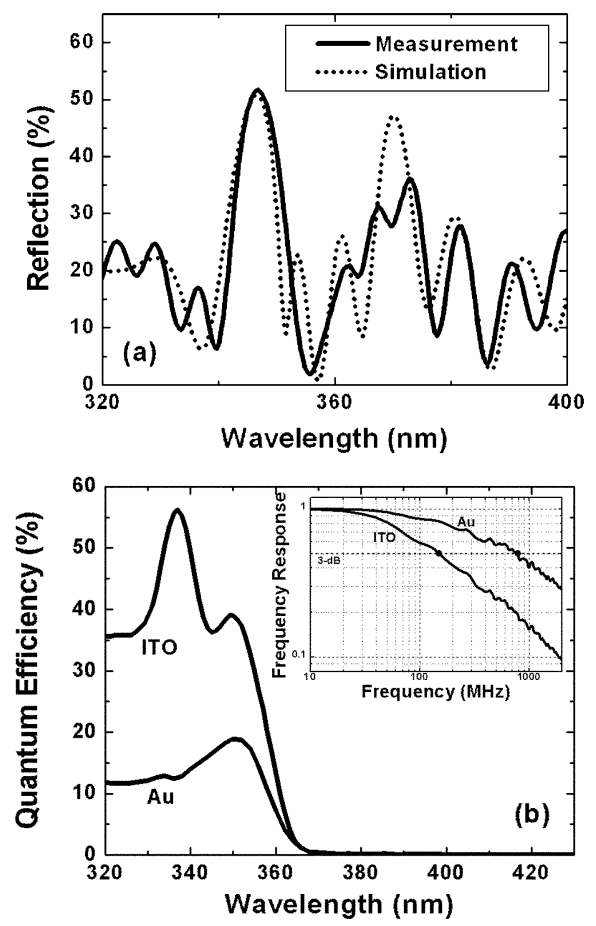

Fig. 3. (a) Measured and simulated spectral reflectivity curves for RCE-AlGaN detector sample. (b) Measured spectral efficiency of RCE-AlGaN Schottky devices with ITO and Au contacts. Inset shows the frequency response of the devices.

microwave probe station. In addition, the spectral reflectivity of RCE samples was measured before device fabrication.

The spectral reflectivity was measured using the same setup used for optical characterization of thin ITO and Au films. I-V measurements were carried out using a semiconductor parameter analyzer and low-noise dc probes. Quantum efficiency measurement setup consisted of a white-light source, monochromator, chopper, and a multimode fiber. The photocurrent was read from a lock-in amplifier and the incident optical power was calibrated with NIST-calibrated detectors. A calibrated Si detector was used for UV and NIR measurements, while IR measurements were calibrated by a Ge detector. Different high-speed setups were used for pulse response measurements in different spectral regions. For high-speed measurements in the UV region, frequency conversion processes with nonlinear crystals were used to generate UV pulses from a femtosecond mode-locked Ti:Sapphire laser. Using second harmonic generation (SHG) and sum frequency generation (SFG) processes, 359- and 267-nm UV optical pulses were generated. For NIR measurements around $820 \mathrm{~nm}$, the adjusted Ti:Sapphire output beam was directly used. The resulting pulse responses were observed on a 50-GHz sampling oscilloscope.

\section{EXPERIMENTAL RESULTS}

\section{A. UV ITO-Schottky Detectors}

Prior to device fabrication, the reflectivity spectrum of the UV RCE photodiode sample was taken and compared to our TMMbased simulation results. Fig. 3(a) shows the experimental and the best theoretically fitted reflectivity curves for this sample. 
Our original simulations predicted a highly reflective mirror between 340 and $380 \mathrm{~nm}$. However, the experimental reflectivity data showed that the long wavelength edge of the mirror had blue-shifted nearly $25 \mathrm{~nm}$ toward $355 \mathrm{~nm}$. This result convinced us that the layers were grown shorter than the original design. A blue-shifted peak reflectivity of $52 \%$ around $345 \mathrm{~nm}$ was measured.

I-V measurements of UV ITO-Schottky devices resulted in high-quality electrical characteristics: low leakage current and high breakdown voltages were observed. Especially, the solarblind (SB) devices exhibited extremely low dark-current density values. The homojunction $\mathrm{GaN}$ sample displayed about six orders of magnitude higher leakage currents. Low leakage currents were measured from RCE-AlGaN detectors.

Fig. 3(b) shows the measured spectral efficiency of UV RCE-Schottky photodiodes with ITO and Au Schottky contacts. ITO-Schottky PDs exhibited a resonant peak of $56 \%$ at $337 \mathrm{~nm}$ under $1-\mathrm{V}$ reverse bias. A weaker resonance was observed in the Au-Schottky sample with a peak efficiency of $19 \%$ at $350 \mathrm{~nm}$, mainly due to the significant absorbtion in metallic Schottky film. In addition, the ITO layer had a reflectivity close to the optimum RCE condition $\left(R_{1}=R_{2} e^{-2 \alpha d}\right)$ which resulted in a stronger enhancement effect [18], where $R_{1}, R_{2}$, and $\alpha$ correspond to the top mirror reflectivity, bottom mirror reflectivity, and absorption coefficient of the active layer, respectively. In our experiment, with $R_{2} \approx 52 \%$, maximum enhancement is achieved with $14 \%$ and $12 \%$ top mirror reflectivity at 350 and $337 \mathrm{~nm}$. A 100-nm-thick ITO film displays a reflectivity of $\sim 16 \%$, which was close to the optimum value of $12 \%$. Reflectivity of Au film (34\% at $350 \mathrm{~nm}$ ), however, deviated significantly from the optimum condition, resulting in a weaker RCE effect.

A similar result was obtained for GaN Schottky samples. Devices with ITO contacts displayed a maximum visible-blind efficiency of $47 \%$, whereas Au-Schottky devices were only able to reach $27 \%$. In the SB spectrum $(\lambda<280 \mathrm{~nm})$; however, ITO-Schottky devices suffered from the increase of UV absorption in ITO, resulting in lower efficiency performance than Au-Schottky devices. A 21\% maximum efficiency at $263 \mathrm{~nm}$ was measured with ITO-Schottky devices, while Au-Schottky detectors displayed $42 \%$ efficiency at $267 \mathrm{~nm}$.

Pulse response measurements at 359 and $267 \mathrm{~nm}$ resulted in 3-dB bandwidths exceeding the gigahertz level. The temporal response was limited by the fall time component. Very fast rise times were measured. The long decay tails can be explained by the carrier trapping effect in AlGaN. Faster pulses were measured under higher reverse bias voltages. Also, faster pulses were obtained with smaller device areas due to reduced RC time constant. The fastest (small area) RCE devices displayed 156 and 77 ps full-width at half-maximum (FWHM) with ITO and Au Schottky contacts, respectively. The fast Fourier transform (FFT) curves of the temporal data are shown in the inset of Fig. 3(b). GaN ITO-Schottky detectors showed faster pulse responses with gigahertz-level 3-dB bandwidths. SB photodiodes exhibited a similar pulse response with fast rise time and long decay component. A summary of the characterization results of UV ITO-Schottky photodiode samples is given in Table III.
TABLE III

AlGaN-BASED ITO-SCHOTTKY PHOTODIODE RESUlts

\begin{tabular}{|c|c|c|c|}
\hline Measured parameter & GaN & $\begin{array}{l}\text { RC'E } \\
\text { AlGaN }\end{array}$ & $\begin{array}{l}\text { SB } \\
\text { AlGaN }\end{array}$ \\
\hline Dark curr. dens. $a-1 \mathrm{~V}\left(\mathrm{~A} / \mathrm{cm}^{2}\right)$ & $\sim 5 \times 10^{-3}$ & $1.3 \times 10^{-3}$ & $<4 \times 10^{-5}$ \\
\hline Breakdown voltage (V) & $\sim 5$ & $\sim 10$ & $>40 \mathrm{~V}$ \\
\hline Turn-on voltage (V) & 0.8 & $\sim 2$ & $\sim 2$ \\
\hline Peak efficiency & $\begin{array}{l}47^{\circ} \% \sigma \\
324 \mathrm{~nm}\end{array}$ & $\begin{array}{l}56^{\circ} 0 \mathrm{a} \\
337 \mathrm{~nm}\end{array}$ & $\begin{array}{l}21^{\circ} \circ \alpha \\
263 \mathrm{~nm}\end{array}$ \\
\hline Peak responsivity $(\mathrm{mA} / \mathrm{W})$ & 130 & 152 & 44 \\
\hline Cut-off (nm) & 363 & 357 & 274 \\
\hline UVVIS rejection & $1.5 \times 10^{3}$ & $\sim 1 \times 10^{3}$ & $-2 \times 10^{3}$ \\
\hline FWHM (ps) & 60 & 156 & 190 \\
\hline 3-dB bandwidth & $2.6 \mathrm{GHz}$ & $150 \mathrm{MHz}$ & $1.1 \mathrm{GHz}$ \\
\hline
\end{tabular}

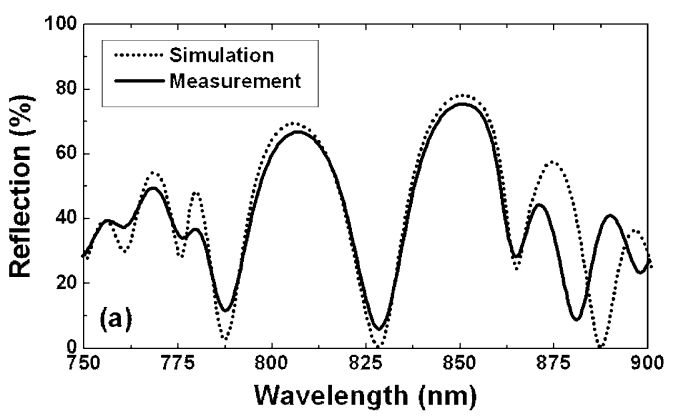

(a)

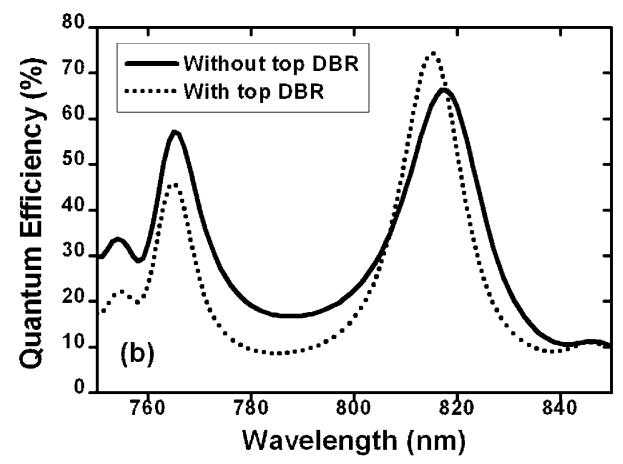

(b)

Fig. 4. (a) Experimental and computational spectral reflectivity data for RCE-AlGaAs wafer. (b) Quantum efficiency measurement of RCE-AlGaAs ITO-Schottky photodiode before and after top DBR deposition.

\section{B. NIR ITO-Schottky Detectors}

Fig. 4(a) shows the measured and calculated spectral reflectivity of the RCE-AlGaAs detector wafer. Simulations agreed well with the experimental data. A resonance dip around the design wavelength of $820 \mathrm{~nm}$ was observed. The I-V measurements resulted in breakdown voltages around $8 \mathrm{~V}$ and typical dark current densities of $5 \times 10^{-5} \mathrm{~A} / \mathrm{cm}^{2}$ at $-1 \mathrm{~V}$ bias. Schottky barrier height and the ideality factor of the ITO-GaAs Schottky contacts were determined as $0.74 \mathrm{eV}$ and 1.12 , respectively.

As can be seen in Fig. 4(b), spectral photoresponse measurements demonstrated the RCE effect clearly. Before the top DBR deposition, a resonant peak around $817 \mathrm{~nm}$ was observed. The peak efficiency before dielectric mirror deposition was $66 \%$. Our simulations predicted an improvement in the efficiency performance with an additional top DBR. With a 2-pair $\mathrm{Si}_{3} \mathrm{~N}_{4} / \mathrm{SiO}_{2}$ Bragg mirror, the top mirror reflectivity increased from $\sim 0 \%$ to $\sim 15 \%$ around the resonance wavelength. The 


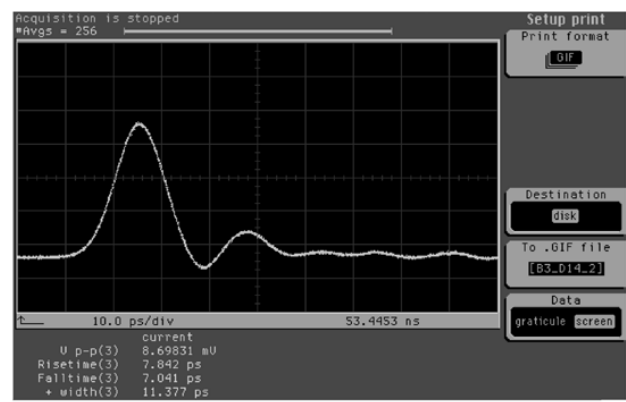

(a)
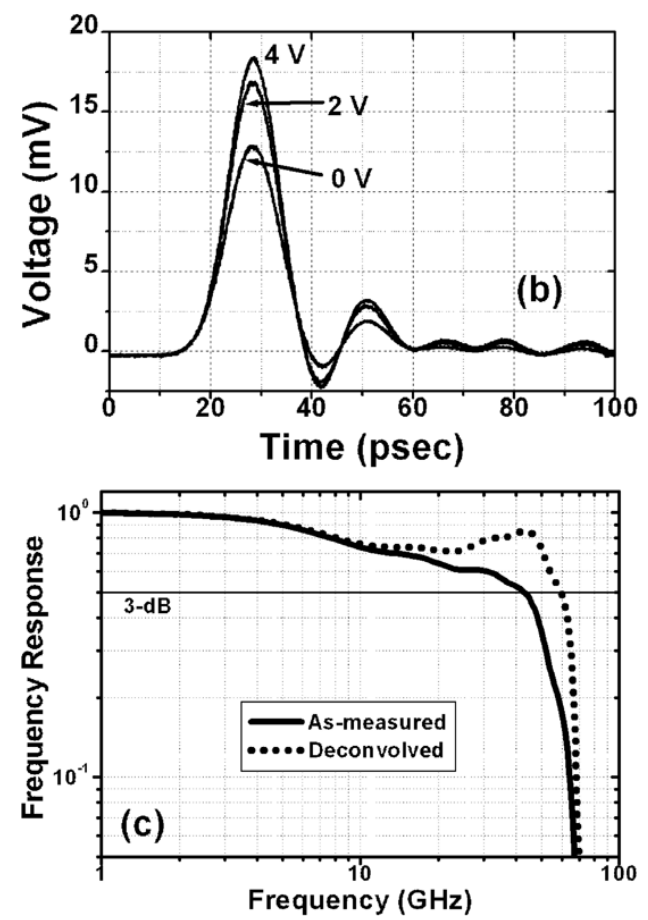

Fig. 5. (a) Measured pulse response of a $5 \times 5 \mu \mathrm{m}^{2}$ ITO-Schottky RCE-AlGaAs photodiode. (b) Bias dependence of pulse response. (c) Corresponding as-measured and deconvolved FFT curves of the temporal response at $4 \mathrm{~V}$ reverse bias.

higher top mirror reflectivity resulted in a better RCE effect which led to an improvement in efficiency performance. The peak efficiency increased to $75 \%$ and the resonance wavelength shifted toward $815 \mathrm{~nm}$.

This result represents a five-fold enhancement over the efficiency of a single-pass detector with the same absorption layer thickness. The wavelength selectivity also increased with higher top mirror reflectivity: FWHM values of the resonant peak decreased from 21 to $15 \mathrm{~nm}$. The peak-to-valley ratio exceeded eight after top mirror deposition.

Very fast pulse responses were measured with small-area RCE-AlGaAs ITO-Schottky photodetectors. The best results were obtained from the smallest $\left(5 \times 5 \mu \mathrm{m}^{2}\right)$ devices. Fig. 5(a) shows an ultrafast measured response displayed on the oscilloscope screen by such an ITO-Schottky device. The output pulse was almost symmetric with setup limited rise and fall times. The bias dependence of pulse response is shown in Fig. 5(b). Slightly faster response was achieved under reverse bias. The FWHM decreased from 12 to 11.2 ps at $4-\mathrm{V}$ bias. The corresponding frequency response of the temporal data
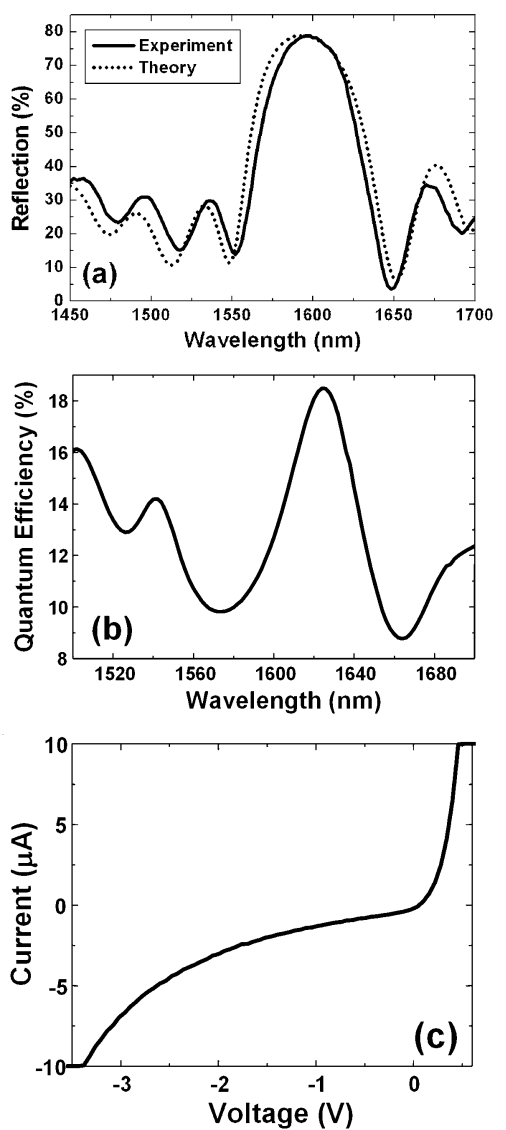

Fig. 6. (a) Measured and simulated spectral reflectivity of RCE InAlGaAs detector wafer. (b) Measured spectral quantum efficiency of the sample at zero bias. (c) Typical I-V curve of ITO-Schottky InAlGaAs photodiode.

taken at 4-V reverse bias is shown in Fig. 5(c). The FFT of the as-measured temporal data had a 3-dB bandwidth of $43 \mathrm{GHz}$. This was very close to the setup limit of $50 \mathrm{GHz}$. Therefore, the actual device bandwidth was found by deconvolving the scope response. The resulting deconvolved frequency response exhibited a 3-dB bandwidth of $60 \mathrm{GHz}$.

\section{InAlGaAs-Based IR ITO-Schottky Detector}

Fig. 6(a) shows the experimental and computational reflectivity curves of InAlGaAs-based RCE sample. When the measured reflectivity was compared with the simulation results, it was understood that the layers were grown $\sim 4 \%$ thicker than the original design. This growth error shifted the center wavelength of DBR from 1550 to $~ 1610 \mathrm{~nm}$. Resonance dips around 1650 and $1550 \mathrm{~nm}$ were observed. The resonances were located close to the Bragg mirror edges where reflectivity dropped sharply. The lower-than-expected bottom mirror reflectivity resulted in a weak RCE effect.

A resonant peak around $1620 \mathrm{~nm}$ was observed in the spectral photoresponse measurements. Fig. 6(b) shows the measured quantum efficiency of ITO-Schottky photodiode at zero bias. A peak quantum efficiency of $\sim 18 \%$ at $1624 \mathrm{~nm}$ was achieved. This was significantly lower than our predicted peak efficiency of $\sim 55 \%$ at the original design wavelength of $1550 \mathrm{~nm}$. The discrepancy was mainly due to the red-shifted Bragg mirror which resulted in low bottom reflectivity at resonance wavelengths. 

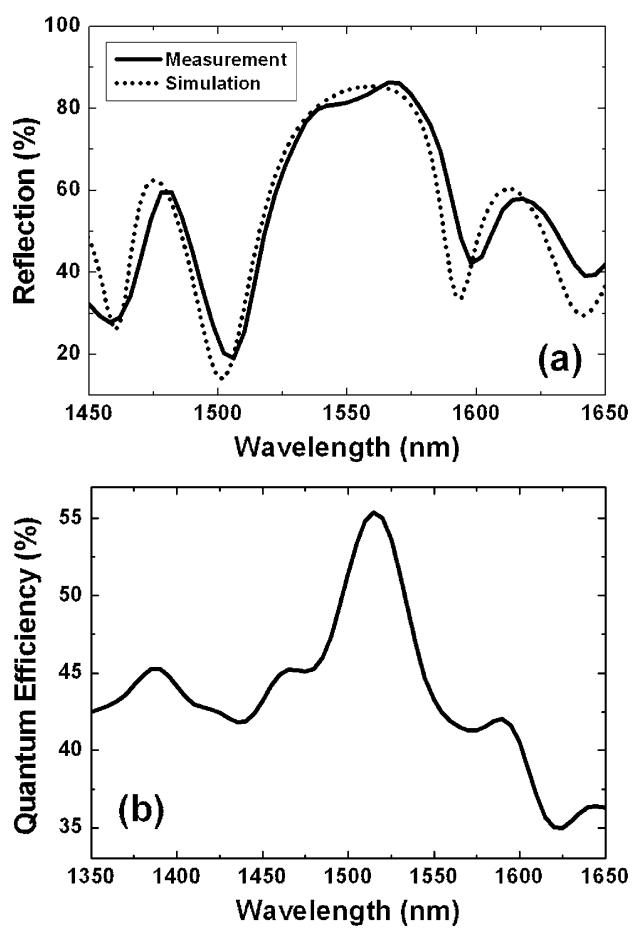

Fig. 7. (a) Measured and simulated spectral reflectivity of RCE InGaAsP detector wafer. (b) Measured photo-voltaic (zero-bias) quantum efficiency spectrum.

Another factor was the decrease in absorption coefficient of InGaAs active layer at the longer resonance wavelength. Nevertheless, a resonant peak with $\sim 2$ peak/valley ratio was achieved with InAlGaAs RCE ITO-Schottky photodiode.

The I-V curve of a 100- $\mu$ m-diameter ITO-Schottky is shown in Fig. 6(c). When compared with UV and NIR ITO-Schottky detectors, higher leakage currents were obtained. This was an expected result since these devices had lower Schottky barriers due to narrower bandgap Schottky material (InAlAs). The small Schottky barrier resulted in significant dark current at room temperature.

\section{InGaAsP-Based IR ITO-Schottky Detector}

The reflectivity characterization of the InGaAsP RCE photodiode wafer showed good agreement with the expected reflectivity spectrum. Fig. 7(a) shows the measured and simulated reflectivity curves. A highly reflecting (80\%) Bragg mirror reflectivity around $1550 \mathrm{~nm}$ was observed. The close agreement between experimental and theoretical results proved that negligible deviation was made in the epitaxial growth process.

I-V measurements resulted in almost linear curves, with no signs of Schottky barrier formation. This result showed that the higher bandgap InGaAsP cap layer did not function successfully as a Schottky barrier enhancement layer. The I-V curves measured showed photoconductor type character.

Resonant peaks were observed in spectral efficiency measurements. Fig. 7(b) shows the measured efficiency performance of an InGaAsP RCE ITO-Schottky photodiode. A peak efficiency of $55 \%$ at $1515 \mathrm{~nm}$ was measured.

\section{DISCUSSION}

In terms of $\mathrm{I}-\mathrm{V}$ characteristics, the best performance was obtained with UV ITO-Schottky devices based on wide bandgap III-nitride alloys. Extremely low dark current and high breakdown voltages were achieved with UV detectors. The leakage currents increased for narrower bandgap materials. Devices with larger areas presented higher dark currents. Schottky contacts on InP-based alloys resulted in highly leaky devices.

Efficiency performance of the fabricated Schottky photodiode samples showed good agreement with transmission and reflection measurement results of ITO and Au films. UV detectors operating in the SB spectrum should prefer $\mathrm{Au}$ instead of ITO contacts due to the strong absorption of ITO for $\lambda<300 \mathrm{~nm}$. ITO showed a highly transparent, lowly reflective characteristic in the visible and IR spectrum. Optical loss in $\mathrm{Au}$ film was close to ITO values for IR wavelengths; however, $\mathrm{Au}$ displayed high reflectivity in this region. ITO, therefore, is an ideal Schottky contact material for single-pass conventional detector structures operating in the VIS-IR spectrum.

High-frequency performance of the ITO-Schottky devices was closely related to the quality of epitaxial material. UV detectors suffered from large defect density and trap sites in AlGaN alloy, which resulted in slowly decaying pulse response due to the collection process of trapped carriers. Another important speed-limiting factor was the series resistance of the devices. The large series resistance of the SB AlGaN sample resulted in a slower pulse response when compared with the higher leakage GaN sample. NIR ITO-Schottky devices based on well-developed low-defect density AlGaAs material exhibited very fast pulse response.

\section{CONCLUSION}

ITO-Schottky photodiodes on various material systems were fabricated. Detector operation was demonstrated for wavelengths ranging from UV to IR spectrum. Enhancement of efficiency performance was achieved with RCE detector structures. Excellent dark current and high speed performance was obtained with UV and NIR ITO-Schottky detectors, respectively. First, ITO-Schottky-based RCE photodetector operation around $1550 \mathrm{~nm}$ was demonstrated using InAlGaAs and InGaAsP heterostructures. It was shown that ITO-Schottky photodetectors can be used for high-performance detection in the near-UV, VIS, and NIR spectrum.

\section{REFERENCES}

[1] M. Razeghi, "Optoelectronic devices based on III-V compound semiconductors which have made a major scientific and technological impact in the past 20 years," IEEE J. Select. Topics Quantum Electron., vol. 6, pp. 1344-1354, 2000.

[2] S. Donati, Photodetectors: Devices, Circuits, and Applications. Upper Saddle River, NJ: Prentice-Hall, 2000.

[3] K. Kishino, M. S. Unlu, J. I. Chyi, J. Reed, L. Arsenault, and H. Morkoc, "Resonant cavity enhanced (RCE) detectors," IEEE J. Quantum Electron., vol. 27, pp. 2025-2034, 1991.

[4] M. S. Unlu and S. Strite, "Resonant cavity enhanced (RCE) photonic devices," J. Appl. Phys. Rev., vol. 78, pp. 607-639, 1995.

[5] K. Kato, "Ultrawide-band/high-frequency photodetectors," IEEE Trans. Microwave Theory Tech., vol. 47, pp. 1265-1281, 1999. 
[6] E. Ozbay, I. Kimukin, N. Biyikli, O. Aytur, M. Gokkavas, G. Ulu, M. S. Unlu, R. P. Mirin, K. A. Bertness, and D. H. Christensen, "Highspeed $>90 \%$ quantum efficiency $p-i-n$ photodiodes with a resonance wavelength adjustable in the 795-835 nm range," Appl. Phys. Lett., vol. 74, pp. 1072-1074, 1999.

[7] E. Ozbay, M. S. Islam, B. M. Onat, M. Gokkavas, O. Aytur, G. Tuttle, E. Towe, R. H. Henderson, and M. S. Unlu, "Fabrication of high-speed resonant cavity enhanced Schottky photodiodes," IEEE Photon. Technol. Lett., vol. 9, pp. 672-674, 1997.

[8] M. S. Unlu, M. Gokkavas, B. M. Onat, E. Ata, E. Ozbay, R. P. Mirin, K. J. Knopp, K. A. Bertness, and D. H. Christensen, "High bandwidth-efficiency resonant cavity enhanced Schottky photodiodes for 800-850 nm wavelength operation," Appl. Phys. Lett., vol. 72, no. 21, pp. 2727-2729, 1998.

[9] C. Lennox, H. Nie, P. Yuan, G. Kinsey, A. L. Holmes, B. G. Streetman, and J. C. Campbell, "Resonant-cavity InGaAs-InAlAs avalanche photodiodes with gain-bandwidth product of $290 \mathrm{GHz}$," IEEE Photon. Technol. Lett., vol. 11, pp. 1162-1164, 1999.

[10] K. Kato, A. Kozen, Y. Muramoto, Y. Itaya, T. Nagatsuma, and M. Yaita, "110-GHz, 50\% efficiency mushroom-mesa waveguide $p-i-n$ photodiode for a 1.55-mm wavelength," IEEE Photon. Technol. Lett., vol. 6, pp. 719-721, 1994.

[11] K. Giboney, R. Nagarajan, T. Reynolds, S. Allen, R. Mirin, M. Rodwell, and J. Bowers, "Traveling-wave photodetectors with 172-GHz and 76-GHz bandwidth-efficiency product," IEEE Photon. Technol. Lett., vol. 7, pp. 412-414, 1995.

[12] Y. H. Aliyu, D. V. Morgan, and R. W. Bunce, "Thermal stability of indium-tin-oxide/n-GaAs Schottky diodes," Electron. Lett., vol. 28, pp. 142-144, 1992.

[13] D. G. Parker, P. G. Say, and A. M. Hansom, " $110 \mathrm{GHz}$ high-efficiency photodiodes fabricated from indium tin oxide/GaAs," Electron. Lett., vol. 23, pp. 527-528, 1987

[14] W. A. Wohlmuth, J.-W. Seo, P. Fay, C. Caneau, and I. Adesida, "A high-speed ITO-InAlAs-InGaAs Schottky-barrier photodetector," IEEE Photon. Technol. Lett., vol. 9, pp. 1388-1390, 1997.

[15] N. Biyikli, I. Kimukin, O. Aytur, M. Gokkavas, M. S. Unlu, and E. Ozbay, " $45-\mathrm{GHz}$ bandwidth-efficiency resonant-cavity-enhanced ITO-Schottky photodiodes," IEEE Photon. Technol. Lett., vol. 13, pp. 705-707, 2001.

[16] N. Biyikli, T. Kartaloglu, O. Aytur, I. Kimukin, and E. Ozbay, "Highspeed visible-blind GaN-based indium-tin-oxide Schottky photodiodes," Appl. Phys. Lett., vol. 79, pp. 2838-2840, 2001.

[17] N. Biyikli, I. Kimukin, T. Kartaloglu, O. Aytur, and E. Ozbay, "Highspeed solar-blind photodetectors with indium-tin-oxide Schottky contacts," Appl. Phys. Lett., vol. 82, pp. 2344-2346, 2003.

[18] N. Biyikli, T. Kartaloglu, O. Aytur, I. Kimukin, and E. Ozbay, "HighSpeed visible-blind resonant cavity enhanced AlGaN Schottky photodiodes," MRS Internet J. Nitride Semicond. Res., vol. 8, 2003.

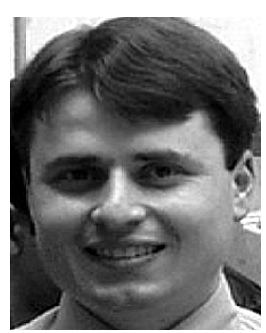

Necmi Biyikli (S'01) was born in Utrecht, The Netherlands, in 1974. He received the B.S. and M.S. degrees in electrical and electronics engineering from Bilkent University, Ankara, Turkey, in 1996 and 1998, respectively. Currently he is working toward the Ph.D. degree at the same institution.

$\mathrm{He}$ has worked with $\mathrm{AlGaAs,} \mathrm{InAlGaAs/InP,}$ $\mathrm{InSb} / \mathrm{InAs}$, and GaN/AlGaN material systems. During his Ph.D. research, he has (co)authored more than 30 refereed journal articles and conference proceedings. His research interests include design, fabrication, and characterization of high-performance photodetectors, high-speed optoelectronic devices, solar-blind UV photodiodes, III-nitride alloys, wide bandgap semiconductors, and physics and applications of nanostructures, nanoscale photonics, and electronic devices.

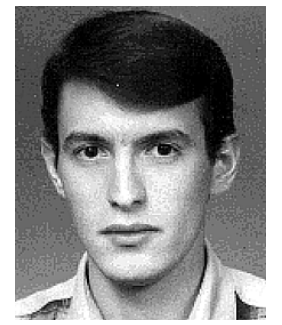

Ibrahim Kimukin (S'00) was born in Edirne, Turkey, in 1976. He received the B.S. degree from Middle East Technical University, Ankara, Turkey, in 1997, and the M.S. degree from Bilkent University, Ankara, in 1999. He is currently working toward the $\mathrm{Ph} . \mathrm{D}$. degree at the same university.

In his research, he designed, fabricated and tested photodetectors grown with III-V semiconductor materials such as GaAs, AlAs, AlGaAs, InGaAs, InAlAs, InP, InGaAsP, InAs, InSb, and GaSb. He also worked on wide-bandgap materials such as $\mathrm{GaN}$, and $\mathrm{AlGaN}$ for high-performance solar blind photodetectors. He has (co)authored more than 30 journal papers and conference proceedings.

Bayram Butun (S'02) Photograph and biography not available at the time of publication.

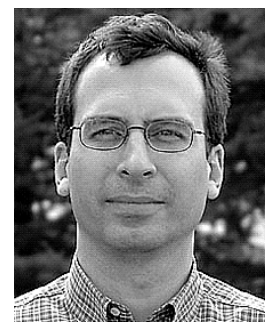

Orhan Aytür (M'94-SM'00) was born in Ankara, Turkey, in 1965. He received the B.S. degree in electrical engineering from Middle East Technical University, Ankara, Turkey, in 1986, and the M.S. and $\mathrm{Ph} . \mathrm{D}$. degrees in electrical engineering from Northwestern University, Evanston, IL, in 1988 and 1991.

He worked as a Laser Scientist at Fibertek, Inc., and as a Research Associate at the University of New Mexico in 1991 and 1992. He joined the Department of Electrical Engineering, Bilkent University, Ankara, in 1993, where he is presently a Professor. His research interests include nonlinear frequency conversion of lasers, quantum optics, and high-performance photodetectors.

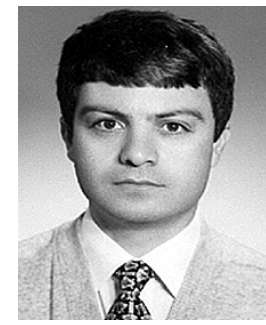

Ekmel Ozbay (M'98) was born on March 25, 1966, in Ankara, Turkey. He received the B.S. degree in electrical engineering from the Middle East Technical University, Ankara, in 1983 and the M.S. and Ph.D. degrees in electrical engineering from Stanford University, Stanford, CA, in 1989 and 1992.

From 1992 to 1994 , he worked as a Scientist at the DOE Ames National Laboratory, Iowa State University, in the area of photonic band gap materials. $\mathrm{He}$ joined the faculty of the Physics Department, Bilkent University, Ankara, in December 1994, where he is currently a Full Professor. His research includes GaN-based devices, photonic crystals, silicon micromachining, and high-speed optoelectronics. He has authored or coauthored more than 160 articles in scientific journals, conference proceedings, and books.

Dr. Ozbay is the 1997 recipient of the Adolph Lomb Medal of Optical Society of America. He is currently acting as a Topical Editor for Optics Letters. 